\title{
Nonlinear Finite-Element Analysis of Double-Skin Steel-Concrete Composite Shear Wall Structures
}

\author{
Ma Xiaowei, Nie Jianguo, and Tao Muxuan
}

\begin{abstract}
Shear wall structures have been widely used in high-rise buildings due to their good lateral resistant behavior. As a new type of shear wall structure, the double-skin steel-concrete composite shear wall has high loading capacity, superior ductility and good crack resistant behavior. The mechanical properties of the composite walls need to be further studied. Based on the general FE package MSC.Marc(2005r2), an elaborate finite element analysis of the double-skin steel-concrete composite shear wall is conducted to simulate the whole-process behavior of the shear wall. The load-displacement relationship is obtained, and the slippage characteristic of the steel plate-concrete interface is also intensively investigated through enforcing the spring elements at the interface. Finally, the influence of the axial compression ratio and the steel plate thickness is presented by a parametric analysis. The conclusions drawn from the analysis are that the maximum slippage of the shear wall occurs at the tension side of the wall bottom where the concrete cracks and the axial force-moment curve has a parabolic property. The relevant conclusions are useful for the routine design practice of tall buildings.
\end{abstract}

Index Terms-Axial force-moment interactive curve, double-skin steel-concrete composite shear wall, finite element analysis, slippage.

\section{INTRODUCTION}

More high-rise buildings are being built during resent years. The ability to resist lateral force plays an important role in earthquake. Shear walls are widely used for their good performance in resisting lateral forces. As a new kind of shear wall structure, double skin steel-concrete composite shear walls have high capacity and good ductility compared to traditional shear walls and they can be used in high-rise buildings with good efficiency for energy dissipation and seismic performance.

Many researchers have studied the composite walls during recent years. In 1991, the new kind of structure was tested by Wright, and the design methods for composite columns and beams were proposed [1]. The structure was developed by Wright with the design of profiled composite shear walls [2]. Link proposed the design which combines the steel plates with stiffening plates and it was used in offshore structures [3]. The local buckling of steel plate of the composite walls were studied by Liang,Q.Q in 2004 [4]. The development of

Manuscript received March 14, 2013; revised May 23, 2013. This work was supported in part by the National Natural Science Foundation of China (Grant No. 90815006) and the "Twelfth Five-Year" plan major projects supported by National Science and Technology (Grant No. 2011BAJ09B01).

The authors are with Tsinghua University, Department of Civil Engineering, Beijing, China (e-mail: mxw11@ mails.tsinghua.edu.cn, niejg@mails.tsinghua.edu.cn, taomuxuan@mails.tsinghua.edu.cn). the Bi-steel composite wall system was summarized by Xie and Chapman [5]. Tae-Sung Eom tested the composite shear walls in 2009 [6]. The results indicated that the composite walls need to be strengthened at the base. These studies focused on the experimental performance of the composite shear walls, whose finite element models have not been studied. In this paper, a nonlinear finite-element analysis model of the composite shear walls is built to study the lateral force resisting performance and the slippage property of the composite shear wall. The ultimate capacity is studied and parameter analysis for the thickness of steel plate and axial force ratio is done. The results are compared with existing results.

\section{StRUCTURE OF THE COMPOSITE WALL}

The composite shear walls consist of two steel plates with studs inside and two steel tubes with concrete filled aside. The distributing bars are set in the concrete, as shown in Fig. 1. The shear walls are located at the bottom of the buildings, and the side columns are worked as flexural resisting part and the mid wall is worked as shear force resisting part when earthquake occurs or wind blows.

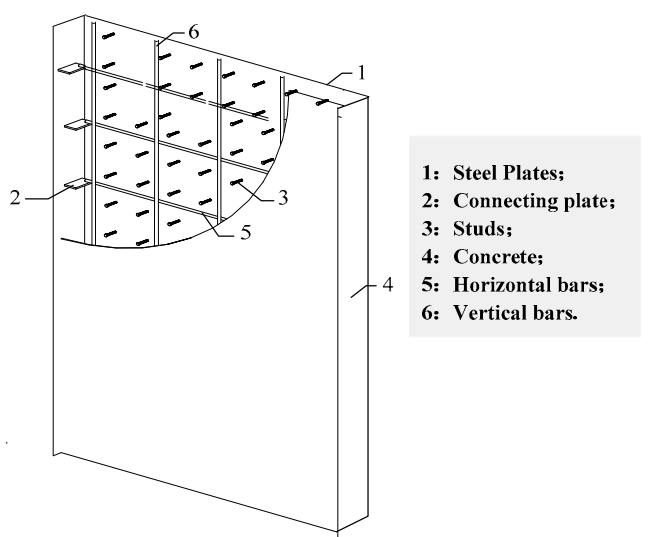

Fig. 1. Structure of double skin steel - concrete composite shear wall

In this paper, the finite model is proposed and it will simulate the loading process of the composite walls subjected to axial force and lateral force. MSC. MARC(2005r2) is used for the FEA on the composite walls for its good efficiency and accuracy.

\section{Finite ELEMENT Model}

\section{A. Material Properties}

The uniaxial stress- strain relation of concrete is modeled using the curve proposed by Hognestad [7] as 


$$
\sigma_{c}=\left\{\begin{array}{lc}
f_{c}^{\prime}\left[2 \varepsilon / \varepsilon_{c 0}-\left(\varepsilon / \varepsilon_{c 0}\right)^{2}\right] & \left(0<\varepsilon \leq \varepsilon_{c 0}\right) \\
f_{c}^{\prime}\left(1-0.15 \frac{\varepsilon-\varepsilon_{c 0}}{\varepsilon_{c u}-\varepsilon_{c 0}}\right) & \left(\varepsilon_{c 0}<\varepsilon \leq \varepsilon_{c u}\right)
\end{array}\right.
$$

where $\varepsilon_{\mathrm{c} 0}=0.002 ; \varepsilon_{\mathrm{cu}}=0.038 ; f_{\mathrm{c}}^{\prime}=0.8 f_{\mathrm{cu}}$.

The concrete in side column is modeled using the curve proposed by Han Linhai [8]. The formula can be expresses as follows:

$$
\sigma_{c}= \begin{cases}\sigma_{\mathbf{0}}\left[\mathbf{2} \varepsilon / \varepsilon_{c c 0}-\left(\varepsilon / \varepsilon_{c c 0}\right)^{2}\right] & \left(\mathbf{0}<\varepsilon \leq \varepsilon_{c c 0}\right) \\ \frac{\sigma_{0} \varepsilon / \varepsilon_{c c 0}}{\beta\left(\varepsilon / \varepsilon_{c c 0}-\mathbf{1}\right)^{\eta}+\varepsilon / \varepsilon_{c c 0}} & \left(\varepsilon>\varepsilon_{c c 0}\right)\end{cases}
$$

where

$$
\begin{aligned}
& \sigma_{0}=\left[1+\left(-0.0135 \xi_{0}^{2}+0.1 \xi_{0}\right)\left(24 / f_{c}^{\prime}\right)^{0.45}\right] f_{c}^{\prime} \\
& \varepsilon_{c c 0}=1300+12.5 f_{c}^{\prime}+\left[1330+760\left(f_{c}^{\prime} / 24-1\right)\right] \xi_{0}^{0.2} \\
& \xi_{0}=A_{s t} f_{y} / A_{c t} f_{c k}
\end{aligned}
$$

$$
\begin{gathered}
\beta=\left(f_{c}^{\prime}\right)^{\mathbf{0 . 1}} /\left(\mathbf{1 . 3 5}\left(\mathbf{1}+\xi_{\mathbf{0}}\right)^{\mathbf{0 . 5}}\right), \text { for } \xi_{0} \text { is not greater than } 3.0 \\
\beta=\left(\mathbf{f}_{\mathbf{c}}^{\prime}\right)^{\mathbf{0 . 1}} /\left(\mathbf{1 . 3 5}\left(\mathbf{1}+\xi_{\mathbf{0}}\left(\xi_{\mathbf{0}}-\mathbf{2}\right)^{\mathbf{2}}\right)^{\mathbf{0 . 5}}\right) \text {, for } \xi_{0} \text { is greater than } 3.0 ; \\
\qquad \begin{array}{c}
f_{c}^{\prime}=\mathbf{0 . 8} f_{c u} ; \\
\eta=\mathbf{1 . 6}+\mathbf{1 . 5} \varepsilon_{c c 0} / \varepsilon ;
\end{array}
\end{gathered}
$$

The smeared cracking model is used for the concrete and three more key parameters need to be defined, which are cracking stress, softening modulus and shear transfer coefficient on the cracking surface.

Based on former studies, the tension softening modulus and the shear transfer coefficient on the cracking surface are set as $3000 \mathrm{~N} / \mathrm{mm}^{2}$ and 0.5 respectively. The cracking stress can be obtained by the following equation [9]:

$$
f_{t}=\mathbf{0 . 2 6 \mathbf { f } _ { c u }}{ }^{2 / 3}
$$

The constitutive curves of concrete are summarized in the Fig. 2.

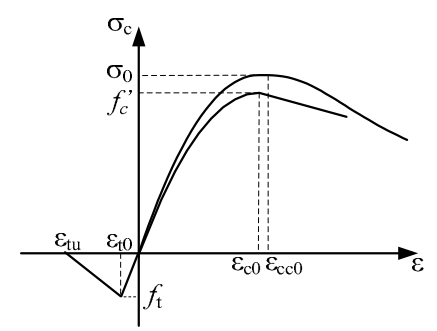

Fig. 2. Uniaxial stress-strain skeleton curves of concrete

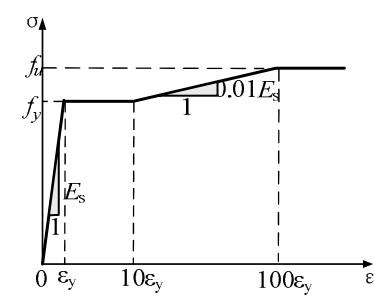

Fig. 3. Uniaxial stress-strain skeleton curves of steel

The uniaxial stress-strain curve of steel plates and steel bars is described as the following four segments of lines in the proposed model [10]. The constitutive curves are shown in Fig. 3. The poisson ratio is set as 0.3 and elastic modulus is set as $2.06 \times 10^{5} \mathrm{~N} / \mathrm{mm}^{2}$. Von Mises yield criterion is proposed to use in the model.

\section{B. Element Type and Element Mesh}

The steel plates are modeled using the shell element of SHELL75, which considers the shear deformation of the elements. The concrete are modeled using the 8-node solid element of SOLID7 and steel bars by Truss9 element.
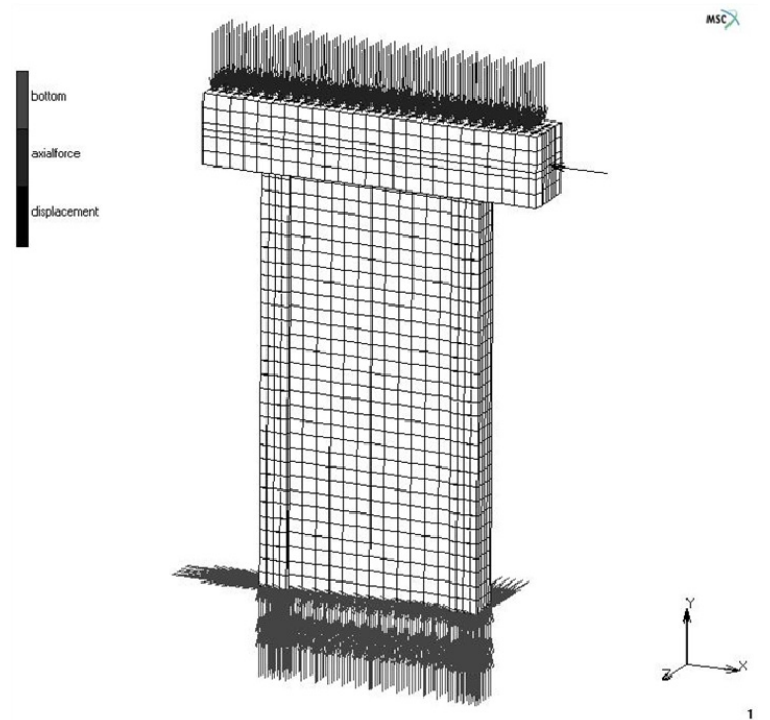

Fig. 4. Finite-element model meshes and boundary conditions

The finite element meshed for both columns and walls are shown in Fig. 4, in which square meshing method is selected to use. Fixed boundary conditions are applied to the bottom of the components and axial forces are applied to the top surface of the wall. By setting lateral force at the center of the top beam, the model can obtain the propertied of the composite shear walls.

\section{Interface of the Steel Plate and Concrete}

The model selects the surface-based interaction with hard contact in the normal direction and spring element in the tangential direction. Experiments of the studs were done to find the load-slippage relation curve, which is key factor for simulating the interface behavior. The widely used curve proposed by Ollgaard [11] is selected for the model. The expression is shown as:

$$
V=V_{u}\left(1-e^{-n s}\right)^{m}
$$

where $s$ is the slippage value, $V_{\mathrm{u}}$ is ultimate capacity of studs, $\mathrm{m}$ and $\mathrm{n}$ is characteristic of the curve, $m=0.558$ and $n=1.0$.

\section{ANALYSIS AND DISCUSSIONS}

The hysteretic curve of the composite wall is obtained by the finite element model, as shown in Fig. 5, from which we can know that the curve is plumper with no sticking of the curve lines. The components are proved good ability for energy dissipation. The skeleton curve obtained from the 
hysteretic curve can be generally divided into three stages:

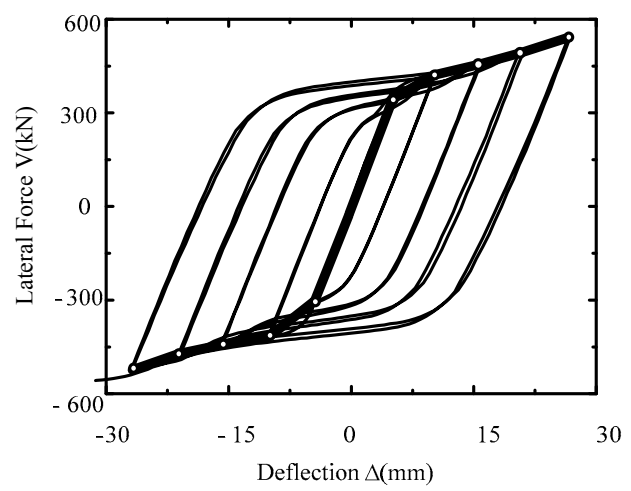

Fig. 5. Loading-displacement hysteretic curve of finite-element result

1) Elastic stage which extends from point $O$ to point $A$. The material can be analyzed as elastic material with fixed modulus at this stage. The components yield for the first time at the point A.

2) Elastic-plastic stage which extends from point $A$ to point B. During the stage, more parts of the components yield and concrete will crack with the increasing of the lateral load. The shear strain of the components reaches the hardening value at the point $\mathrm{B}$.

3) Hardening stage which extends from point $B$ to point $C$. During this stage, the interface force between steel plate and concrete increases and buckling of the steel plates appears. Due to the hardening effect of the materials, the curve shows the features of going upwards.

\section{VERIFICATION}

The skeleton curve of the load-deflection of the composite wall is obtained by the finite element model. To verify the result, a set of tests are selected and they are simulated by the model. The test parameters are listed in Table I.

TABLE I: TEST PARAMETERS OF THE COMPOSITE WALLS

\begin{tabular}{|l|l|l|l|l|l|}
\hline Specimen & $\begin{array}{l}\text { Wall } \\
\text { height } \\
(\mathrm{mm})\end{array}$ & $\begin{array}{l}\text { Shear } \\
\text { span } \\
\text { ratio }\end{array}$ & $\begin{array}{l}\text { RC wall } \\
\text { thickness } \\
(\mathrm{mm})\end{array}$ & $\begin{array}{l}\text { Axial } \\
\text { force } \\
(\mathrm{kN})\end{array}$ & $\begin{array}{l}\text { Plate } \\
\text { thickness } \\
(\mathrm{mm})\end{array}$ \\
\hline CSW-1 & 800 & 2.0 & 90 & 589 & 3.0 \\
\hline CSW-2 & 800 & 1.5 & 90 & 630 & 3.0 \\
\hline CSW-3 & 800 & 1.5 & 90 & 770 & 3.0 \\
\hline CSW-4 & 800 & 1.5 & 90 & 1026 & 3.0 \\
\hline
\end{tabular}

The specimens are tested subjected to axial force and bending moment, as shown in Fig. 6. The sections of the specimens are the same, while the shear span ratio and axial forces are defined with different values to find the effect to the composite walls.

The failure modes of the composite walls are beam-column failure during the process of the test. The specimens are proved good ductility and large ultimate capacity.

The comparing figures between the tests and the model are shown in Fig. 7. The initial stiffness of the model fits well that of the tests, and the ultimate capacity predicted has good accuracy as well.

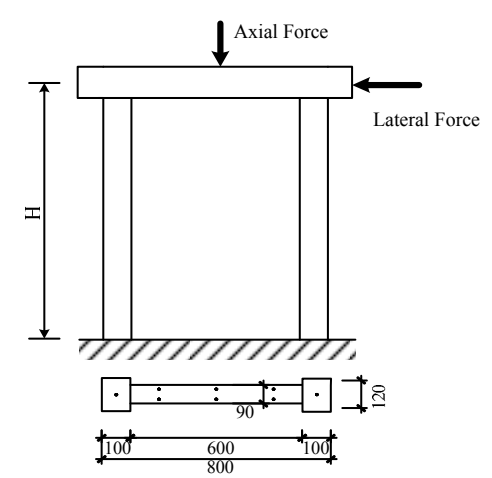

Fig. 6. Basic parameters of the calculation example

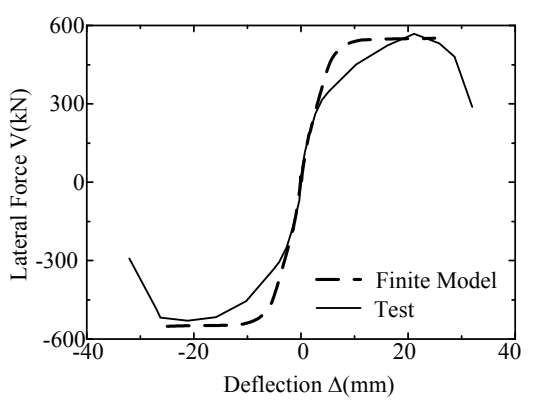

(a) CSW-1

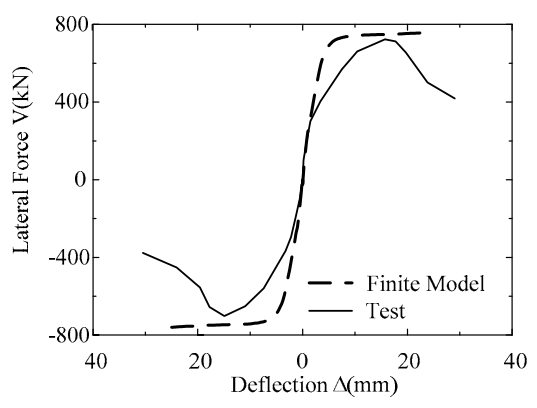

(b) $\mathrm{CSW}-2$

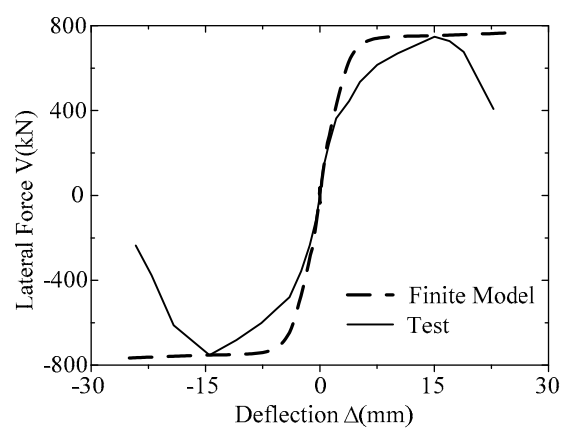

(c) CSW-3

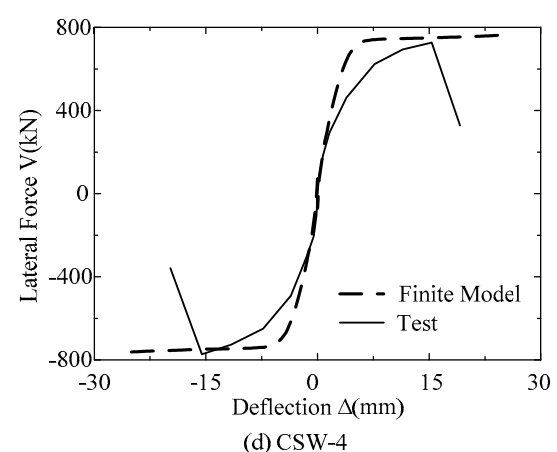

Fig. 7. Comparison of skeleton curve between the tests and finite models

Table II lists the ratio of the finite element results to the test 
results. The average error is $1.3 \%$ based on the values of $M_{\mathrm{u} 1} / M_{\mathrm{u} 2}$, which proves the good accuracy of the predicting results of the finite element model.

TABLE II: COMPARISON BETWEEN THE FINITE ELEMENT AND THE TEST
\begin{tabular}{|c|c|c|c|}
\hline Specimen & $\begin{array}{c}\text { Finite Element } \\
V_{\mathrm{u} 1}(\mathrm{kN} \cdot \mathrm{m})\end{array}$ & $\begin{array}{c}\text { Test } \\
V_{\mathrm{u} 2}(\mathrm{kN} \cdot \mathrm{m})\end{array}$ & $M_{\mathrm{u} 1} / M_{\mathrm{u} 2}$ \\
\hline CSW-1 & 551.27 & 552.25 & 0.998 \\
\hline CSW-2 & 759.57 & 735.10 & 1.033 \\
\hline CSW-3 & 767.03 & 769.25 & 0.997 \\
\hline CSW-4 & 762.15 & 751.30 & 1.014 \\
\hline
\end{tabular}

\section{SlipPage ANALYSIS}

The interface force of between steel plates and concrete leads to the slippage of the interface, which will affect the performance for resisting shear force of the composite shear wall. The slippage values overall the wall at the largest displacement are obtained by the value of steel plate minus the value of concrete from the finite element model, as shown in Fig. 8. The slippage mainly occurs at the bottom of the wall, and the maximum slippage is nearly $1.0 \mathrm{~mm}$ when the largest displacement of the loading point is $30 \mathrm{~mm}$.

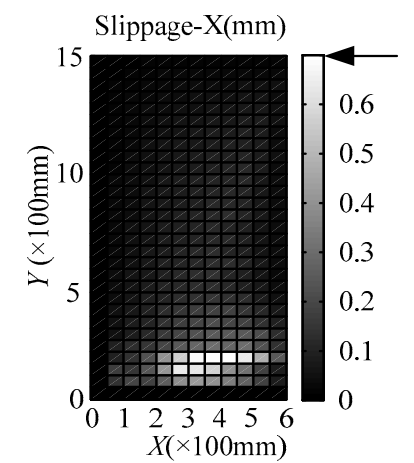

(a) $\mathrm{X}$ direction

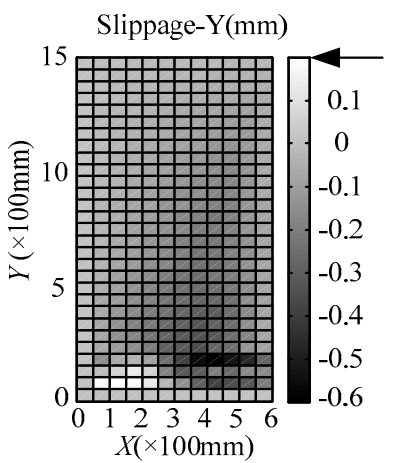

(b) $\mathrm{Y}$ direction
Fig. 8. Slippage distribution of $\mathrm{X}$ direction and $\mathrm{Y}$ direction

The slippage of $\mathrm{X}$ direction occurs mainly at the $\mathrm{Y}$ direction between $0 \mathrm{~mm}$ and $200 \mathrm{~mm}$. The largest value is 0.7 $\mathrm{mm}$ and no negative value exists. The slippage of $\mathrm{Y}$ direction presents positive and negative alternating and the maximum value is $0.6 \mathrm{~mm}$ which occurs at the tension region. With the increasing of lateral force, the neutral axis move with the cracking of concrete. In the compression part, the slippage value is positive and in the tension part the slippage value is negative. Due to the buckling of the steel plate, the slippage at the bottom turns into large values compared to top region. The results provide important basis for designing the composite wall, especially for the studs design.

\section{PARAMETER ANALysis}

The effect of axial force ratio is analyzed by the parameter analysis, in which the axial force-moment curve can be obtained, as shown in Fig. 9.

The ultimate moment increases with the increasing of axial force which locates at a low level, while it will decrease when the axial force increases in a high level larger than the boundary point. Based on the regularity, the maximum axial force undertaken by the shear wall can be obtained and it will guide the practice engineering design.

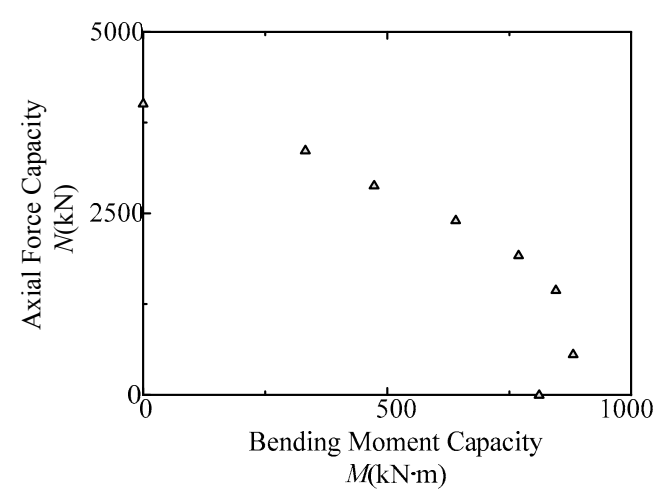

Fig. 9. Parametric analysis result of axial compression ratio

The steel plate plays an important role in lateral force resisting. As shown in Fig. 10, the $M / M_{\mathrm{u}}-N / N_{\mathrm{u}}$ curve becomes cambered outwards with the increase of steel ratio. The ratio of $M$ to $M_{\mathrm{u}}$ is larger than that with a smaller steel ratio, which leads to larger relative ratio value of $N / N_{\mathrm{u}}$ as well.

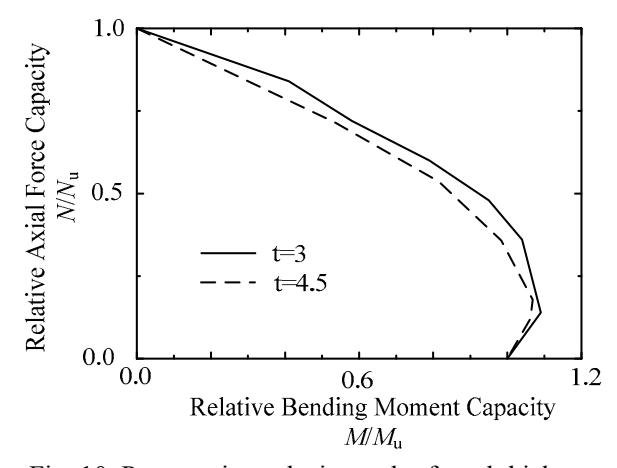

Fig. 10. Parametric analysis result of steel thickness

\section{CONCLUSION}

The finite element model of double skin steel-concrete composite shear wall is proposed based on the MSC.MARC (2005r2). The load-deflection curve is obtained and the slippage is considered and analyzed in the model. Parameter analysis is done to find the influence of the axial force ratio and steel ratio on the ultimate capacity of the composite wall. Based on the analysis, the conclusions are drawn as follows:

a. The curve of load-deflection of the composite shear wall subjected to axial force and lateral force can be divided in three stages, the third stage of which will decide the ultimate capacity of the composite shear wall.

b. The maximum slippage of the shear wall occurs at the tension side of the wall bottom where the concrete cracks. The studs need to be tightly set at the points.

c. The axial force-moment curve has a parabolic property and the turning point occurs at the point of ultimate capacity. This regularity will be the guide for the engineering design of the composite shear wall.

\section{ACKNOWLEDGMENT}

The authors acknowledge the valuable suggestions from Prof. Fan JS, Department of Civil Engineering from time to time during completion of this paper. 


\section{REFERENCES}

[1] H. D. Wright, T. O. S. Oduyemi, and H. R. Evans, "The experimental behavior of double skin composite elements," Journal of Constructional Steel Research, vol. 19, pp. 97-110, Feb. 1991.

[1] H. D. Wright, "The behaviour of composite walling under construction and service loading," Journal of Constructional Steel Research, vol. 35, pp. 257-273, Mar. 1995.

[2] R. A. Link and E. Elwia, "Composite concrete steel plate walls: analysis and behavior," Journal of Structural Engineering-ASCE, vol. 121, pp. 260-271, Feb. 1995.

[2] Q. Q. Liang, B. Uy, H. D. Wright, and M. A. Bradford, "Local buckling of steel plates in double skin composite panel under biaxial compression and shear," Journal of Structural Engineering-ASCE, vol. 130, pp. 443-451, Mar. 2004

[3] M. Xie and J. C. Chapman, "Developments in sandwich construction," Journal of Constructional Steel Research, vol. 62, pp. 1123-1133, Nov. 2006.

[4] T. S. Eom, "Behavior of double skin composite wall subjected to in-plane cyclic loading," Journal of Structural Engineering-ASCE, vol. 135, pp. 1141-1149, Oct. 2009.

[5] E. Hognestad, "Concrete Stress Distribution in ultimate Strength Design,” ACI Journal, vol. 52, pp. 455-479, Dec. 1955.

[6] L. H. Han, G. H. Yao, and Z. Tao, "Performance of concrete-filled thin-walled steel tubes under pure torsion," Thin-Walled Structure, vol. 45, pp. 24-36, Feb 2007.

[7] J. G. Nie and M. X. Tao, "Theory of seismic response analysis of steel-concrete composite structures using fiber beam elements," Journal of Building Structure, vol. 32, pp. 35-44, Oct. 2011.

[8] M. Elchalakani, X. L. Zhao, and R. H. Grzebieta, "Concrete-filled circular steel tubes subjected to pure bendin," Journal of Constructional Steel Research, vol. 57, pp. 1141-1168, May. 2001.
[9] J. G. Ollgaard and R. G. Slutter, "Fisher J.W. Shear strength of stud connectors in lightweight and normal-weight concrete," EAISC Engineering, vol. 8, pp. 55-64, May. 1971.

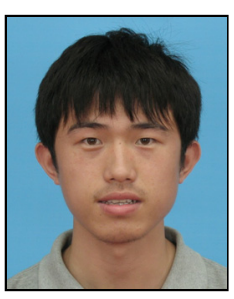

X. W. Ma is a PhD Candidate with Tsinghua University, Department of Civil Engineering in Beijing, China. He received the bachelor degree of civil engineering in Tsinghua University in 2011. His research is focused on the composite structures in tall buildings and bridges.

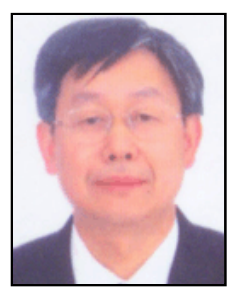

J. G. Nie is professor with Tsinghua University, Department of Civil Engineering in Beijing, China. His research is focused on the composite structures in tall buildings and bridges.

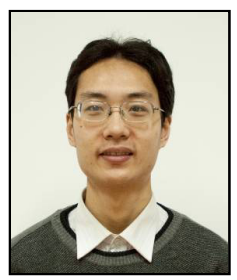

X. W. Ma is a $\mathrm{PhD}$ with Tsinghua University, Department of Civil Engineering in Beijing, China. He received the PHD degree of civil engineering in Tsinghua University in 2012. His research is focused on the composite structures in tall buildings and bridges. 